\title{
Pervasion degree of convective mixing and investigations of mantle mixing*
}

\author{
Rongshan $\mathrm{Fu}^{1,2,3, \uparrow} \quad$ Jianhua Huang ${ }^{1,2,3} \quad$ Jun Liu ${ }^{1,2,3}$ and $\quad$ Xiaohua Chang ${ }^{1,2,3}$ \\ ${ }^{1}$ National Geophysical Observatory at Mengcheng, Mengcheng 233500, China \\ ${ }^{2}$ Key Laboratory of Crust-Mantle Materials and Environments, Chinese Academy of Science, Hefei 230026, China \\ ${ }^{3}$ School of Earth and Space Science, University of Science and Technology of China, Hefei 230026, China
}

\begin{abstract}
Geodynamic studies have shown that mantle convection is like a giant blender to make the original heterogeneous mantle mixing and homogenizing. However, some models, especially from geochemical data show that the modern mantle may still contain a number of reservoir bodies with different chemical composition. Then, the modern mantle is homogeneous? Authors have defined a box replacement degree of convective mantle mixing and pervasion degree of convective mantle mixing (that equals to initial density of tracing elements divided by final density of tracing elements) to investigate the mantle mixing. The previous results have shown that after four billion years the mantle is basic uniform and the box replacement of the convective mantle is more than $80 \%$ in steady-state convection models. This paper calculates and discusses the pervasion degree of convective mantle mixing in detail. For the initial state we will set some $10^{\circ} \times 10^{\circ}$ (spacing $0.25^{\circ}$ ) tracing boxes, which includes 1681 tracer, at the top and bottom of the mantle, and then track the motions of these tracers, and investigate the convective mixed pervasions. The results show that at the initial stage though the convective mixing pervasions are very different from mode to mode, after running for some time, the convective mixing pervasions for most modes are going to be a constant and the tracers are more evenly distributed in the whole mantle.
\end{abstract}

Key words: mantle mixing; mantle convection; box replacement degree; pervasion degree CLC number: P315.2 Document code: A

\section{Introduction}

Mantle mixing, as a basic problem of the evolution of the Earth, particularly of the mantle, is faced in the studies on geophysics, geochemistry and geodynamics over the past two decades. Moreover, it can not be avoided in the study of the mantle thermodynamics. Analysis of the incompatible tracing elements in the magma rocks from the mantle showed that these rocks are divided into two categories. One is from the mid-oceanic ridge basalt (MORB), in which the mantle rock is interpreted as the result of partial melting, showing a loss of some elements, called depleted mantle $(\mathrm{DMM})$. And the other is called ocean-island basalt (OIB), like Hawaii's island, interpreted as from the deeper mantle plume. Comparing with the MORB, it is relative enrichment of elements and geochemists think it

\footnotetext{
* Received 1 April 2009; accepted in revised form 27 May 2009; published 10 August 2009.

- Corresponding author. e-mail: frs@ustc.edu.cn
}

comes from an original mantle or primitive mantle (PM). Many studies simply use these geochemical data to define the difference between the upper and lower mantle so as to explain the structure of the mantle convection (Hofmann and White, 1982; Hoffman and McKenzie, 1985; Hofmann, 1997; Alle gre et al, 1986; O’Nions, 1987; Loper, 1985; Grand et al, 1997; van der Hilst et al, 1997; Monnereau and Quere, 2001; Gurnis and Davies, 1986). But with the geochemical data accumulation this simple division can not explain new observations, so some geochemists suggest that there are many chemical reservoirs in the mantle (Hofmann and White, 1982; Hofmann, 1997). Some studies suppose that there are enormous reservoirs with different chemical composition in the mantle. These chemical reservoirs could preserve in a long geological time going with differentiated mantle from the original Earth (Hart and Zindler, 1986; Ten et al, 1998; Becker et al, 1999). Based on these observations and theoretical speculation, the modern mantle may still maintain the status of non-uniform. This raises a question that modern mantle is evenly? In the 
processes of mantle evolution, convection will play what role in mantle mixing?

Over a period of time, numerical simulation methods are employed to investigate the mantle mixing. The study in 2D or 3D space domain shows that on the conditions of existed toroidal field even a steady convection is also able to generate effective mixing (Ferrachat and Ricard, 1998; Schmalzl et al, 1996). van Keken and Zhong (1999) studied the mantle mixing problem in a $3 \mathrm{D}$ spherical region on the conditions of the modern mantle convection and took the revised Luyaponov index to evaluate the degree of mantle mixing. The results show that the main factors to control the mantle mixing efficiency are the driving force of the slabs (in particular circum-Pacific region) and the toroidal components of modern plate movement. Relatively speaking, the Earth's mantle has been mixed effectively after a longterm evolution and could not keep some isolated blocks in it (van Keken and Ballentine, 1998, 1999). Meantime, some regional or specific characteristics of the mixing problem have also been discussed (Walzer and Hendel, 1999; Kellogg et al, 2002; Farnetani et al, 2002).

In order to improve the accuracy of the Luyaponov index the grid points of the computed models are going to be more and more. However, grid refinement not only needs large-scale parallel computing, but also is difficult to provide a complete mantle mixing framework. At the same time, Luyaponov index is to determine the separation degree of the arbitrarily small initial fragments in a convective system only, but could not give the replacements for whole-mantle material (the replacement degrees of the convective system). As for this case, we put forward a more intuitive way to investigate the mantle mixing, which is to define the box replacement degree of convective mantle mixing and pervasion degree of convective mantle mixing, and compute the box replacement degree of convective mantle mixing in detail, and conclude that the Earth's mantle is mixed very well passing four billion years (Fu et al, 2007). Assuming that there is a stable convection system in the mantle driven by plate motions and density anomalies as well, this paper calculates and analyzes the pervasion degree of convective mantle mixing by the same method.

\section{Pervasion degree of convective man- tle mixing and mantle convection model}

This study uses a stable convection model developed by Fu et al $(2005,2007)$, in which the mantle con- vection is driven by the modern plate movement and the density anomaly of the mantle (Figure 1). If the mantle is divided into upper and lower mantle at $660 \mathrm{~km}$ depth $\left(r=660 / R_{\mathrm{LMB}}\right)$ and their average viscosity are $v_{1}$ and $v_{2}$ respectively (Figure 1), the radial component $W_{1}$ and $W_{2}$ of the velocity can be written as

$$
\begin{aligned}
W_{1}= & \sum_{l} \sum_{m}\left\{\left[\left(E_{l}^{m} r^{l}+F_{l}^{m} r^{l+2}+G_{l}^{m} r^{-(l+1)}+H_{l}^{m} r^{-(l-1)}\right) .\right.\right. \\
& \cos m \phi+\left(\bar{E}_{l}^{m} r^{l}+\bar{F}_{l}^{m} r^{l+2}+\bar{G}_{l}^{m} r^{-(l+1)}+\bar{H}_{l}^{m} r^{-(l-1)}\right) . \\
& \sin m \phi]+\sum_{k} \frac{\mathrm{g} \alpha R_{1}^{4} l(l+1)}{v_{1} \beta_{k}^{4} \sqrt{r}} \cdot Q_{1 / 2}\left(\beta_{k} r\right){ }_{k} C_{l}^{m} \cos m \phi+ \\
& \left.\left.{ }_{k} D_{l}^{m} \sin m \phi\right]\right\} P_{l}^{m}(\cos \theta) \\
& \text { for } R_{660} / R_{1} \leq r \leq R_{\mathrm{LMB}} / R_{1},
\end{aligned}
$$

and

$$
\begin{aligned}
W_{2}= & \sum_{l} \sum_{m}\left\{\left[\left(K_{l}^{m} r^{l}+L_{l}^{m} r^{l+2}+M_{l}^{m} r^{-(l+1)}+N_{l}^{m} r^{-(l-1)}\right)\right.\right. \\
& \cos m \phi+\left(\bar{K}_{l}^{m} r^{l}+\bar{L}_{l}^{m} r^{l+2}+\bar{M}_{l}^{m} r^{-(l+1)}+\bar{N}_{l}^{m} r^{-(l-1)}\right) \\
& \sin m \phi]+\sum_{k} \frac{\mathrm{g} \alpha R_{1}^{4} l(l+1)}{v_{2} \beta_{k}^{4} \sqrt{r}} \cdot Q_{1 / 2}\left(\beta_{k} r\right){ }_{k} C_{l}^{m} \cos m \phi+ \\
& \left.\left.{ }_{k} D_{l}^{m} \sin m \phi\right]\right\} P_{l}^{m}(\cos \theta) \\
& \text { for } R_{\mathrm{CMB}} / R_{1} \leq r \leq R_{660} / R_{1},
\end{aligned}
$$

where $\theta$ and $\phi$ are latitude and longitude; $R_{1}$ is taken as $R_{\mathrm{LMB}}, R_{\mathrm{CMB}}$ and $R_{660}$, which are the radius of the bottom of lithosphere (LMB), core-mantle boundary (CMB) and

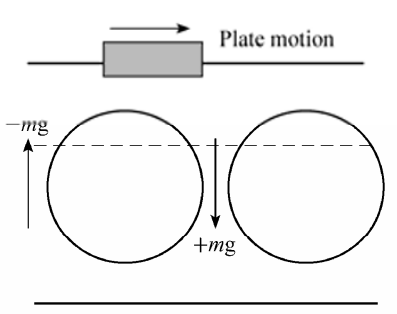

(a)

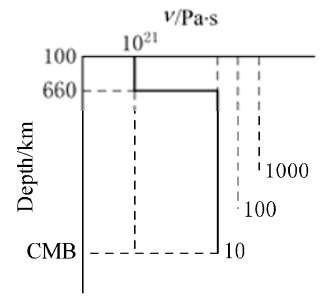

(b)

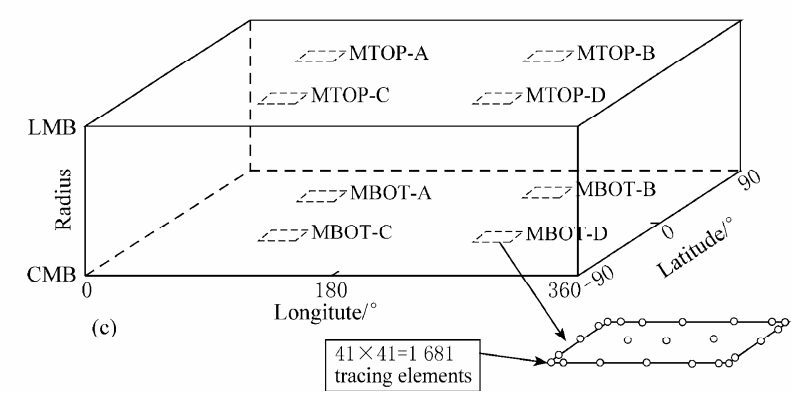

Figure 1 Scheme of mantle convection model and the mantle viscous structure. (a) Driving forces of mantle convection; (b) Viscous structure of the mantle where the value $10,100,1000$ is viscosity ratio $v_{2} / v_{1}$ between lower and upper mantle; (c) Initial position and tracing elements of modes (see Table 1 in the text). 
$660 \mathrm{~km}$ discontinuous, respectively; $\mathrm{g}$ is the gravity acceleration and $\alpha$ is thermal expansion coefficient. The first term of the right hand of equation (1) is the general solution, where $E_{l}^{m}, F_{l}^{m}, G_{l}^{m}, H_{l}^{m}, \bar{E}_{l}^{m}, \bar{F}_{l}^{m}, \bar{G}_{l}^{m}, \bar{H}_{l}^{m}$, $K_{l}^{m}, L_{l}^{m}, M_{l}^{m}, N_{l}^{m}, \bar{K}_{l}^{m}, \bar{L}_{l}^{m}, \bar{M}_{l}^{m}$ and $\bar{N}_{l}^{m}$ are the constants determined by the boundary conditions. The second one is the special solution corresponding to the density anomaly of the mantle, in which it expands to the spherical Bessel function as

$$
\begin{gathered}
Q_{1 / 2}\left(\beta_{k} r\right)=\mathrm{J}_{-1 / 2}\left(\beta_{k} \eta\right) \mathrm{J}_{1 / 2}\left(\beta_{k} r\right)- \\
\mathrm{J}_{1 / 2}\left(\beta_{k} \eta\right) \mathrm{J}_{-1 / 2}\left(\beta_{k} r\right),
\end{gathered}
$$

where $\beta_{k}$ is the zero points of the spherical Bessel function in the region of $1-\eta$, where $\eta$ is expressed by $R_{\mathrm{CMB}} / R_{1}$.

On certain conditions, we can understand the convective process in a non-uniform material system as a homogenization process of the system. In other words, the convective mixing process for a particular anomaly region in a system is an anomaly material pervasion process to the whole system. If put $M$ tracing elements into a small box with a volume $\Delta V$ at the initial time, the density of tracing elements is

$$
\rho_{0}=\frac{M}{\Delta V} .
$$

When the convection is operating, we can calculate the distributed volume $V$ of the $M$ tracing elements, so we have the density of tracing elements is

$$
\rho=\frac{M}{V} \text {. }
$$

Then we define the pervasion degree of convective mantle mixing as

$$
K=\frac{\rho}{\rho_{0}}=\frac{V}{\Delta V} .
$$

\section{Model computation and analysis}

The viscosity ratio of the upper mantle and lower mantle is set to be 1:100. The driving forces of the mantle convection will take three models: by the plate motions only, by the mantle density anomaly only and by above two driving forces synchronously. In view of calculating time on computer, we only select the plate motions as the driving force of the mantle convection. The plate motion model is Nuvell_1 and the plate movements are expanded to 20 degree and order spherical harmonic functions for poloidal and toroidal field, respectively. We have shown that the results of this driving force model do not affect the final results for discussing the mantle mixing (Fu et al, 2007).

In order to discuss the pervasion degree of the mantle mixing in detail, we calculate eight test box modes at $100 \mathrm{~km}$ depth (MTOP-A, B, C, D) and $100 \mathrm{~km}$ above CMB (MBOT-A, B, C, D), respectively. The positions of these boxes are listed in Table 1 . The volume of the test box is $10^{\circ} \times 10^{\circ} \times 0.625 \mathrm{~km}$ and every box contains $41 \times 41=1681$ tracing elements and its gap is $0.25^{\circ}$. In the computation the time interval is taken as 500 thousand years. We calculate 8000 steps for four billion year. For each test box mode the computation time approximately is eleven hours. We can track each tracing element to investigate the box replacement degree and the pervasion degree of convective mantle mixing. If dividing the mantle into $36 \times 15 \times 9=4860$ blocks with size $10^{\circ} \times 10^{\circ} \times 300 \mathrm{~km}$, the box replacement degree of the convective mantle mixing is listed in Table 1 , too. We find that except MBOT-C, the box replacement degree for each mode is over $45 \%$, which shows that the paths of 1681 tracing elements for most modes have swept more than $50 \%$ mantle blocks.

Fu et al (2007) defined an apparent density to discuss the pervasion degree of convective mantle mixing

Table 1 Computation models and their box replacement degree of convective mantle mixing

\begin{tabular}{llcc}
\hline \multirow{2}{*}{ Mode } & Position of box & & \multicolumn{2}{c}{ Box replacement degree } \\
\cline { 3 - 4 } & & Whole mantle & Upper mantle \\
\hline MTOP-A & $45^{\circ} \mathrm{N}-55^{\circ} \mathrm{N}, 89^{\circ} \mathrm{E}-99^{\circ} \mathrm{E}$ & $75.32 \%$ & $83.64 \%$ \\
MTOP-B & $45^{\circ} \mathrm{N}-55^{\circ} \mathrm{N}, 269^{\circ} \mathrm{E}-279^{\circ} \mathrm{E}$ & $53.15 \%$ & $62.80 \%$ \\
MTOP-C & $35^{\circ} \mathrm{S}-45^{\circ} \mathrm{S}, 89^{\circ} \mathrm{E}-99^{\circ} \mathrm{E}$ & $48.11 \%$ & $62.15 \%$ \\
MTOP-D & $35^{\circ} \mathrm{S}-45^{\circ} \mathrm{S}, 269^{\circ} \mathrm{E}-279^{\circ} \mathrm{E}$ & $60.29 \%$ & $74.80 \%$ \\
MBOT-A & $45^{\circ} \mathrm{N}-55^{\circ} \mathrm{N}, 89^{\circ} \mathrm{E}-99^{\circ} \mathrm{E}$ & $65.27 \%$ & $74.24 \%$ \\
MBOT-B & $45^{\circ} \mathrm{N}-55^{\circ} \mathrm{N}, 269^{\circ} \mathrm{E}-279^{\circ} \mathrm{E}$ & $46.51 \%$ & $59.10 \%$ \\
MBOT-C & $35^{\circ} \mathrm{S}-45^{\circ} \mathrm{S}, 89^{\circ} \mathrm{E}-99^{\circ} \mathrm{E}$ & $16.95 \%$ & $62.70 \%$ \\
MBOT-D & $35^{\circ} \mathrm{S}-45^{\circ} \mathrm{S}, 269^{\circ} \mathrm{E}-279^{\circ} \mathrm{E}$ & $60.05 \%$ & $42.80 \%$ \\
\hline
\end{tabular}


conveniently. In this case, the definition of an equivalent volume is $\delta V=\Delta \theta \cdot \Delta \phi \cdot \Delta r$ (degree $\times$ degree $\times$ spacing of united ratio). The pervasion process of mode MTOP-A is illustrated in Figure 2. This figure shows that how the 1681 initial tracing elements limited in a small box expand in the whole mantle gradually. Because we use a rectangular coordinate system to describe the problem in a spherical coordinate system, so there presents a big spacing region in Figure 2 for one billion year. In fact, in the spherical coordinate system longitude 0 degree is the same as longitude 360 degree. Figure 3 shows the distribution of the 1681 tracing elements for the eight initial position models after operating four billion years. In this figure may see intuitively, except MBOT-C, the 1681 tracing elements for each test box almost flood in the whole mantle, even each group of tracing elements at the different initial positions correspond to different convective mixing processes. The identical region in the mantle possibly contains many tracing elements from different initial boxes. It means that the convection process causes the material from the different initial point in the mantle to be mixed. Meanwhile, we find a special region in the mantle, where the distribution of tracing elements is circular-like. This is a special phenomenon and it infers that the convection streamline
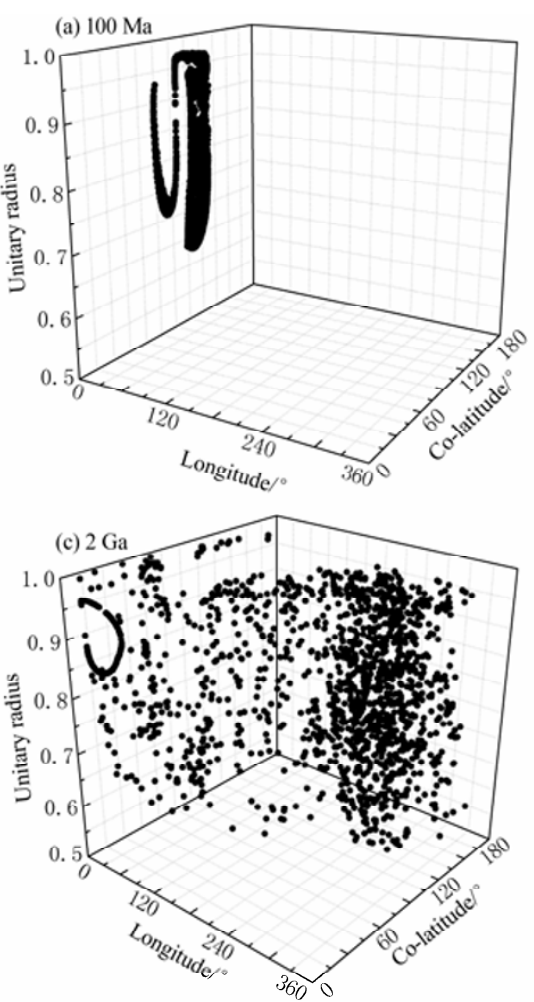

will be closed in this region.

Figure 4 give the apparent density changes with time for the eight initial test box modes. It can be seen in terms of different modes, that the dependence on the apparent density evolution is very different. At the beginning of the process, the apparent density shows a great difference, and for some models the apparent density fluctuates with time. But over time, their apparent densities gradually tend to a value of a stable region between 0.0067 and 0.0072 . Table 2 lists the apparent density and the pervasion degree of convective mantle mixing after four billion years running of the system for the eight initial position modes. It can be seen that the pervasion degree of convective mantle mixing is stable with the values between $4.0 \times 10^{-7}$ and $4.3 \times 10^{-7}$.

Table 2 Apparent density of the eight modes

\begin{tabular}{|c|c|c|c|}
\hline Mode & $\begin{array}{c}\text { Initial density } \rho_{0} \\
/\left(10^{5}\right. \\
\left.\text { count } /\left(1^{\circ} \times 1^{\circ} \times 1 \mathrm{~km}\right)\right)\end{array}$ & $\begin{array}{c}\text { Final density } \rho \\
/\left(10^{-3}\right. \\
\left.\text { count } /\left(1^{\circ} \times 1^{\circ} \times 1 \mathrm{~km}\right)\right)\end{array}$ & $\begin{array}{c}\text { Pervasion } \\
\text { degree } \\
K / 10^{-8}\end{array}$ \\
\hline MTOP-A & 1.6891 & 67.63 & 0.4003 \\
\hline MTOP-B & 1.6891 & 69.90 & 0.4138 \\
\hline MTOP-C & 1.6891 & 67.50 & 0.3996 \\
\hline MTOP-D & 1.6891 & 67.42 & 0.3991 \\
\hline MBOT-A & 1.6891 & 68.54 & 0.4058 \\
\hline MBOT-B & 1.6891 & 68.60 & 0.4061 \\
\hline MBOT-C & 1.6891 & 71.92 & 0.4258 \\
\hline MBOT-D & 1.6891 & 67.48 & 0.3995 \\
\hline
\end{tabular}
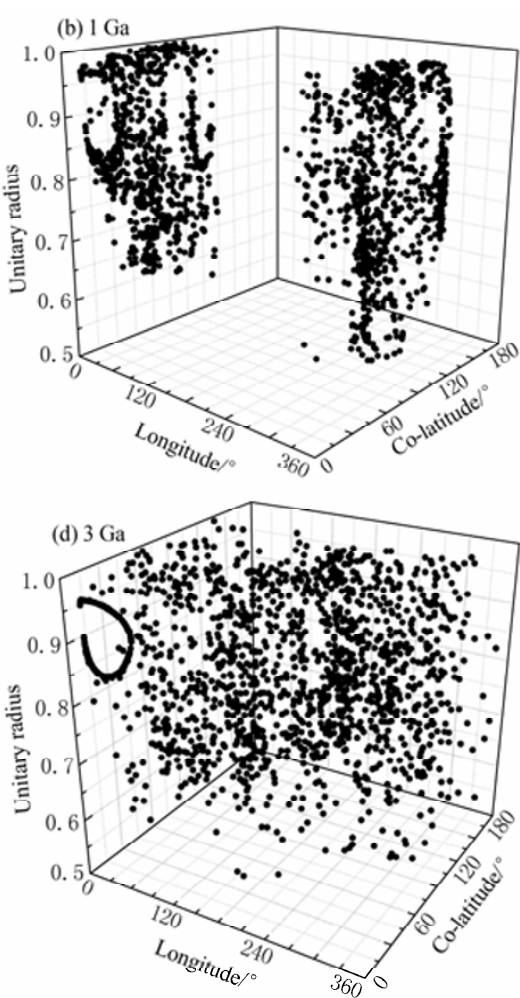

Figure 2 Pervasion process of the mode MTOP-A. 

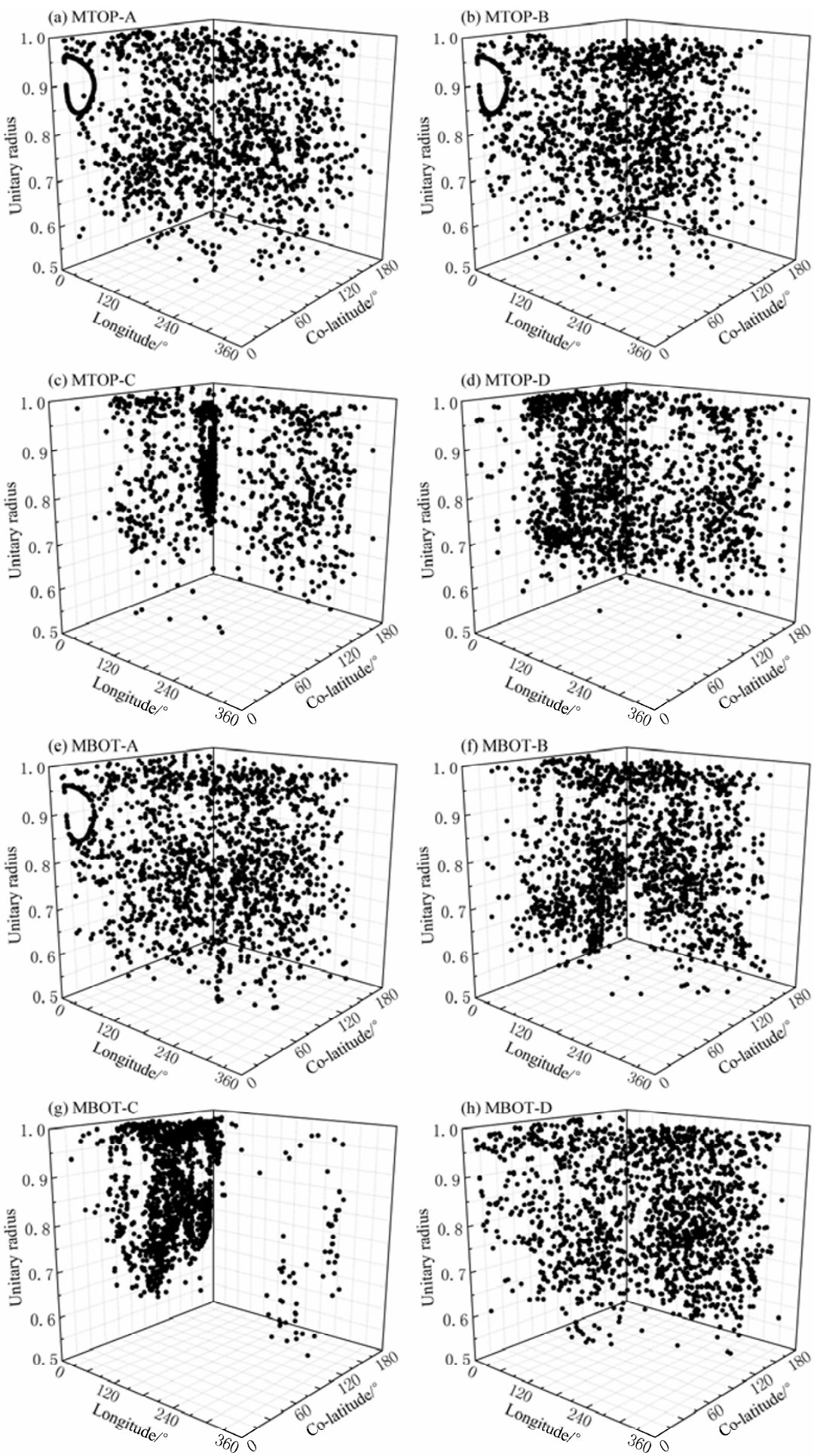

Figure 3 Distributions of 1681 tracing elements for the eight initial position modes after four billion years.

For a more detailed understanding the degree of the mantle mixing in this case, we divide the mantle into 4860 boxes, too. We calculate the contributions of the $13448(8 \times 1681)$ tracing elements to the mantle mixing after four billion years running of the system. That is to count how many empty boxes in the mantle, where are not any tracing elements. In this case, there are 1680 empty boxes, accounting for $30.5 \%$ of the mantle boxes. Perhaps the reason for too many empty boxes is that there is too small number of tracing element for us to estimate 

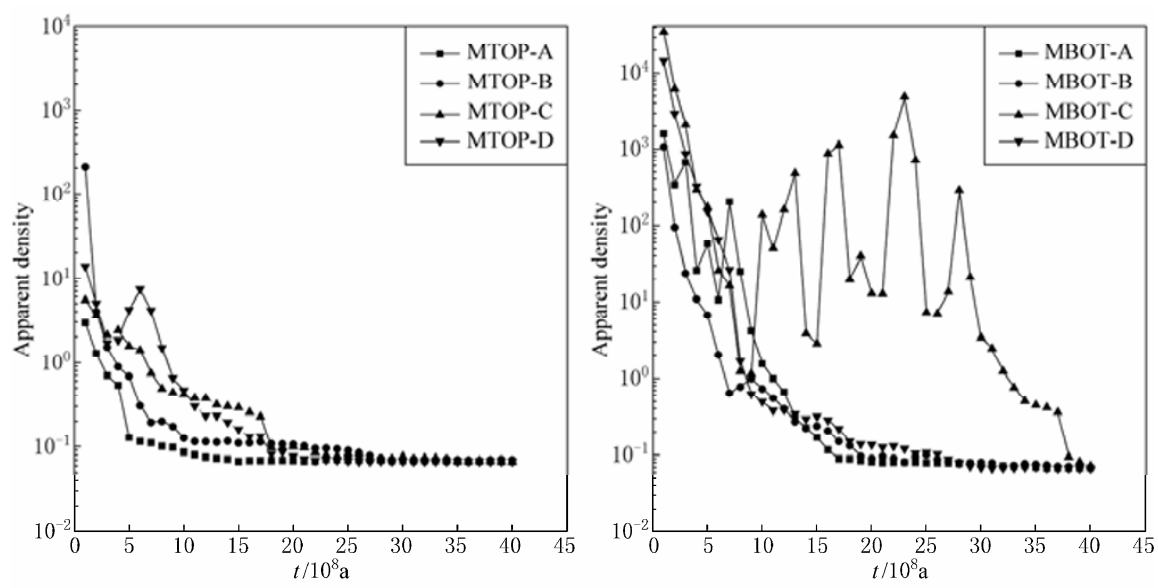

Figure 4 Apparent density changes with time for the eight modes.

the actual degree of mantle mixing. In order to increase the number of the tracing elements, we select 2689600 $(8 \times 1681 \times 200)$ tracing elements in the last 100 million years and $5397200(8 \times 1681 \times 400)$ tracing elements in the last 200 million years. If adding up the number of the empty boxes for the eight modes one by one, the ratio of empty boxes to all boxes of the mantle is $13 \%$ (for 200 time points) and 9.7\% (for 400 time points), respectively (see Table 3 ). In other words, nearly $87 \%$ and $90.3 \%$ of the mantle boxes contain the tracing elements from the eight initial test boxes. It can be expected that this proportion will increase if increasing the number of initial test boxes. From this statistics we can suggest that through four billion years the mantle convective systems can transfer the tracing elements from different location (perhaps with differences in composition) to spread in the whole mantle.

Table 3 Accummulation of empty boxes and the ratio of empty boxes to all mantle boxes

\begin{tabular}{cccccc}
\hline \multirow{2}{*}{ Mode } & \multicolumn{2}{c}{ Case for 200 time points } & & \multicolumn{2}{c}{ Case for 400 time points } \\
\cline { 2 - 3 } \cline { 5 - 6 } & $\begin{array}{c}\text { Number of } \\
\text { mpty boxes }\end{array}$ & $\begin{array}{c}\text { Percent of } \\
\text { empty boxes }\end{array}$ & & $\begin{array}{c}\text { Number of } \\
\text { empty boxes }\end{array}$ & $\begin{array}{c}\text { Percent of } \\
\text { empty boxes }\end{array}$ \\
\hline MTOP-A & 1930 & $39.7 \%$ & 1474 & $30.3 \%$ \\
+MTOP-B & 1469 & $30.2 \%$ & 1096 & $22.6 \%$ \\
+MTOP-C & 1209 & $24.9 \%$ & 882 & $18.1 \%$ \\
+MTOP-D & 895 & $18.4 \%$ & 600 & $12.3 \%$ \\
+MBOT-A & 759 & $15.6 \%$ & 563 & $11.6 \%$ \\
+MBOT-B & 696 & $14.3 \%$ & 512 & $10.5 \%$ \\
+MBOT-C & 689 & $14.2 \%$ & 510 & $10.9 \%$ \\
+MBOT-D & 634 & $13.0 \%$ & 469 & $9.7 \%$ \\
\hline
\end{tabular}

*+MTOP-B means to plus this mode box.

\section{Discussion and conclusions}

In this paper, a simple model is employed to discuss the problem of the mantle mixing by counting the pervasion degree in a convective system. The main conclusion is that on the model conditions the abnormal material limited in small regions, which are located at the top or bottom of the mantle, has been transported to the whole mantle, and its pervasion degree of the mantle mixing is to be a stable value between $4.0 \times 10^{-7}$ and $4.3 \times 10^{-7}$ after four billion years running of the system. The ratio of the empty boxes, where are not any tracing elements, is 13\% (for 200 time points and 2689600 tracers) and $9.7 \%$ (for 400 time points and 5397200 tracers), respectively. This calculation results can be deduced that the abnormal mantle blocks, which were generated in the early stages of mantle formation, may disappear passing about four billion years. In other words, the mantle has basically been mixed. We understand that above conclusions are only in a very simple model. In fact, there is a most important implicit assumption in the computation model, that is, the surviving time of the abnormal material boxes in this model is 100 million years or 200 million years and there is not any new abnormal material box to generate in the mantle. If some abnormal blocks, on certain conditions, can remain isolated and not involved in convection, or the abnormal material of these blocks can supply from the mantle, the above conclusions will not hold.

Corresponding to the above calculated results, there is a very important question. Whether or not there are still large (at least greater than $500 \mathrm{~km}$ ) abnormal blocks in the modern mantle (besides the region of lithosphere and core-mantle boundary)? It will require more extensive and detailed study of the seismic observations. However, there is not any report about it. The fact that the continental crust could not return to the mantle has been proved by geological observations or by theoretical 
calculations, so since the early differentiation of the Earth, the continental crust has floating over the mantle. There is only a very small amount of crustal material to be carried into the mantle, even the deep mantle, in the process of the deep subduction of the continental crust, but most of the crustal blocks, which have been driven in the mantle, will still return to the Earth's crust at last. The study of the deep mantle near the CMB shows much more complex problems. Seismic tomography proves that there are some anomalies in the region of the core-mantle boundary, including low-speed high-density thermo-chemical anomaly body (Ni et al, 2002; $\mathrm{Ni}$ and Helmberger, 2003; Wang and Wen, 2007), very lower velocity region of S-wave (Williams and Garnero, 1996; Williams et al, 1998; Wen et al, 2001; Lay et al, 2004) and the accumulation bodies from subductive plates (Garnero, 2004) and so on. So there still remain lots of questions. For example, these abnormal regions or blocks are the participations in mantle convection? How do they evolve? What is the role of them in the mantle mixing? However, we recognize that because of the simple model in this paper is not a substitute for the real mantle, so when facing the reality, we all need to constantly remind ourselves: there is only one Earth!

Acknowledgments This study was supported by National Natural Science Foundation of China (40574043).

\section{References}

Alle'gre C J, Staudacher T and Sarda P (1986). Rare gas systematics: Formation of the atmosphere, evolution and structure of the Earth's mantle. Earth Planet Sci Lett 81: 127-150.

Becker T W, Kellogg J B and O'Connell R J (1999). Thermal constraints on the survival of primitive blobs in the lower mantle. Earth Planet Sci Lett 171: $351-365$.

Farnetani C G, Legras B and Tackley P J (2002). Mixing and deformations in mantle plumes. Earth Planet Sci Lett 196: 1-15.

Ferrachat S and Ricard Y (1998). Regular vs. chaotic mantle mixing. Earth Planet Sci Lett 155: 75-86.

Fu R S, Han L B, Huang J H and Liu J (2007). Study of the mantle mixing driven by plate motions. Chinese J Geophys 50(5): 1 213-1 222.

Fu R S, Wang Y, Huang J H, Chang X H, Zha X J and Dai Z Y (2005). Effect of rheology structure to flow patterns driving by density anomaly in mantle. Chinese J Geophys 48(4): 900-910 (in Chinese).

Garnero E J (2004). A new paradigm for Earth's core-mantle boundary. Science 304: $834-836$.
Grand S P, van der Hilst R D and Widiyantoro S (1997). Global seismic tomography: A snapshot of convection in the Earth. GSA Today 7: 1-7.

Gurnis M and Davies G F (1986). The effect of depth-dependent viscosity on convective mixing in the mantle and the possible survival of primitive mantle. Geophys Res Lett 13: 541-544.

Hart S R and Zindler A (1986). Chemical geodynamics. Annu Rev Earth Planet Sci 14: 493-571.

Hoffman N R A and McKenzie D P (1985). The destruction of geochemical heterogeneities by differential fluid motions during mantle convection. Geophys J R astr Soc 82: 163-206.

Hofmann A W (1997). Mantle geochemistry: the message from oceanic volcanism. Nature 385: 219-229.

Hofmann A W and White W M (1982). Mantle plumes from ancient oceanic crust. Earth Plannet Sci Lett 57: 421-436.

Kellogg J B, Jacobsen S B and O'Connell R J (2002). Modeling the distribution of isotopic ratios in geochemical reservoirs. Earth Planet Sci Lett 204 183-202.

Lay T, Garnero E J and Williams Q (2004). Partial melting in a thermo-chemical boundary layer at the base of the mantle. Physics Earth Planet Inter 146: 441-467.

Loper D E (1985). A simple model of whole-mantle convection. J Geophys Res 90: $1809-1836$.

Monnereau M and Quere S (2001). Spherical shell models of mantle convection with tectonic plates. Earth Planet Sci Lett 184: 575-587.

Ni S D and Helmberger D (2003). Further constraints on the African superplume structure. Physics Earth Planet Inter 140: 243-251.

Ni S D, Tan E, Gurnis M and Helmberger D (2002). Sharp sides to the African superplume. Science 296: 1 850-1 852.

O’Nions R K (1987). Relationships between chemical and convective layering in the Earth. J Geol Soc London 144: 259-274.

Schmalzl J, Houseman G A and Hansen U (1996). Mixing in vigorous, time-dependent 3D convection and application to the Earth's mantle. $J$ Geophys Res 101: 21 847-21 858.

Ten A A, Podladchikov Y Y, Yuen D A, Larsen T B and Malevsky A V (1998). Comparison of mixing properties in convection with the particle-line method. Geophys Res Let 25: 3 205-3 208.

van der Hilst R D, Widiyantoro S and Engdahl E R (1997). Evidence for deep mantle circulation from global tomography. Nature 386: 578-584.

van Keken P E and Ballentine C J (1998). Whole-mantle versus layered mantle convection and the role of a high-viscosity lower mantle in terrestrial volatile evolution. Earth Planet Sci Lett 156: 19-32.

van Keken P E and Ballentine C J (1999). Dynamical models of mantle volatile evolution and the role of phase transitions and temperature-dependent rheology. J Geophys Res 104: 7 137-7 168.

van Keken P E and Zhong S (1999). Mixing in a 3D spherical model of present-day mantle convection. Earth Planet Sci Lett 171: 533-547.

Walzer U and Hendel R (1999). A new convection-fractionation model for the evolution of the principal geochemical reservoirs of the Earth's mantle. Physics Earth Planet Inter 112: 211-256.

Wang Y and Wen L (2007). Geometry and P and S velocity structure of the "African Anomaly". J Geophys Res 112: B05313, doi:10.1029/2006JB004483.

Wen L, Silver P, James D and Kuehnel R (2001). Seismic evidence for a thermo-chemical boundary at the base of the Earth's mantle. Earth Planet Sci Lett 189: 141-153.

Williams Q and Garnero E J (1996). Seismic evidence for partial melt at the base of Earth's mantle. Science 273: 1528.

Williams Q, Revenaugh J and Garnero E (1998). A correlation between ultra-low basal velocities in the mantle and hot spots. Science 281: 546-549. 